Article

\title{
Non-Isothermal Crystallization Behavior of Poly(vinylidene fluoride) in Dialkyl Phthalate Diluents during Thermally Induced Phase Separation Process
}

\author{
Yakai Lin ${ }^{1}$, Yuanhui Tang ${ }^{2}$, Lin Wang ${ }^{1}$ and Xiaolin Wang ${ }^{1, *}$ \\ 1 Beijing Key Laboratory of Membrane Materials and Engineering, Department of Chemical Engineering, \\ Tsinghua University, Beijing 100084, China; yk_lin@tsinghua.edu.cn (Y.L.); \\ wanglin891208@mail.tsinghua.edu.cn (L.W.) \\ 2 College of Chemistry and Environmental Engineering, China University of Mining and Technology, \\ Beijing 100083, China; tangyuanhui@126.com \\ * Correspondence: xl-wang@tsinghua.edu.cn
}

Received: 3 July 2020; Accepted: 31 August 2020; Published: 3 September 2020

\begin{abstract}
The non-isothermal crystallization behavior of poly(vinylidene fluoride) (PVDF) in dialkyl phthalate diluents during the thermally induced phase separation (TIPS) process was investigated by differential scanning calorimetry (DSC) at various cooling rates. Dialkyl phthalates with different alkyl chain-length, namely dimethyl phthalate (DMP), diethyl phthalate (DEP) and dibutyl phthalate (DBP), were used as the diluent. The effects of alkyl chain-length of dialkyl phthalate and cooling rate on the non-isothermal crystallization behavior as implied by the Avrami analysis modified by Jeziorny and Mo's analysis were determined. The values of half-time, $t_{1 / 2}$, and the parameters $Z_{c}$ and $F(t)$, which characterized the kinetics of non-isothermal crystallization, showed that the crystallization rate increased with the increase of the alkyl chain-length of dialkyl phthalate due to the lower compatibility between PVDF and dialkyl phthalate. Moreover, the alkyl chain-length of dialkyl phthalate also has a great impact on the compact spherulitic structure of PVDF membranes prepared from different PVDF/dialkyl phthalate blends. With the decrease of the alkyl chain-length of dialkyl phthalate, the number of spherulites increased and the size of spherulites became smaller. This research thus not only proves the effects of alkyl chain-length of dialkyl phthalate on the non-isothermal crystallization behavior of PVDF, but also provides a systematic strategy to evaluate a single diluent during the TIPS process.
\end{abstract}

Keywords: poly(vinylidene fluoride); non-isothermal crystallization behavior; dialkyl phthalate; alkyl chain-length; thermally induced phase separation

\section{Introduction}

Microporous semi-crystalline polymeric membranes with controlled pore size, shape and distribution can be prepared via the thermally induced phase separation (TIPS) method, which was first introduced by Castro in the late 1970s [1]. In the TIPS process, an appropriate polymer/diluent system is heated to achieve a homogeneous solution. During cooling, both by isothermal or non-isothermal quenching, TIPS can proceed either solid-liquid phase separation or liquid-liquid phase separation. The solid-liquid phase separation usually results from the crystallization of polymer from the homogeneous solution phase [2]. In the real TIPS process, the non-isothermal step occurs much more often than the isothermal step. Thus, the non-isothermal crystallization behavior of the crystalline polymer in the diluted system would predominate the pore structure of the resulted membrane. 
Poly(vinylidene fluoride) (PVDF), as a semi-crystalline polymer, receives considerable attention as an important membrane material to produce microporous membranes for water treatment processes due to its high mechanical strength, good chemical resistance and thermal stability, as well as excellent chemical resistance against corrosive chemicals [3,4]. A lot of researches have reported the fabrication of PVDF microporous membranes via the TIPS method [5-18]. Most of them focused on the resultant membrane structure, and the spherulite structure was found to be the common structure due to the solid-liquid phase separation occurring. In addition, many of these researchers have adopted dialkyl phthalates (such as dimethyl phthalate (DMP), diethyl phthalate (DEP) and dibutyl phthalate (DBP)) or their mixture to prepare PVDF membranes $[10,12,14,15,18]$. Although solid-liquid phase separation can be found to occur in all of these systems, the structure and performance of these membranes presented as very different due to the different compatibility between PVDF and diluents, and also different PVDF crystallization behavior. Therefore, it is necessary to study the non-isothermal crystallization behavior of PVDF/diluent blend. Ji et al. investigated the non-isothermal crystallization kinetics of PVDF/dibutyl phthalate (DBP)/di(2-ethylhexyl)phthalate (DEHP) blends via TIPS [19]. The results showed that as the DEHP ratio in the diluent mixture increased, the interaction between PVDF and the diluent mixture became weaker, which resulted in the increase of the crystallization rate of PVDF. However, no such work has so far been carried out to analyze the non-isothermal crystallization behavior of PVDF in PVDF/single diluent blend though these single diluents have been widely used in the TIPS process.

Dialkyl phthalates, which have several advantages, such as low volatility and good thermal stability, have been widely used as single diluents in the TIPS process. In this work, three dialkyl phthalates, with similar structure but different alkyl chain-length, including dimethyl phthalate (DMP), diethyl phthalate (DEP) and dibutyl phthalate (DBP), were utilized as the single diluent of PVDF. The effects of alkyl chain-length of dialkyl phthalate on the non-isothermal behavior of PVDF/dialkyl phthalate blends during the TIPS process were investigated by differential scanning calorimetry (DSC) at various cooling rates. The morphologies of PVDF membranes prepared from different PVDF/dialkyl phthalate systems were also studied through scanning electron microscopy (SEM).

\section{Experimental}

\subsection{Materials}

Poly(vinylidene fluoride) (PVDF, Weight average molecular weight is 370,000, the ratio of weight average molecular weight to number average molecular weight is 2.5) was supplied by CMDIC XIAMEN (China). A series of dialkyl phthalate, which were dimethyl phthalate (DMP, Weight average molecular weight is 194.19 , boiling point is $282^{\circ} \mathrm{C}$ ), diethyl phthalate (DEP, Weight average molecular weight is 222.24 , boiling point is $295^{\circ} \mathrm{C}$ ) and dibutyl phthalate (DBP, Weight average molecular weight is 278.35 , boiling point is $340^{\circ} \mathrm{C}$ ), were used as the diluents. All the diluents were analytical grade without further purification.

\subsection{Sample Preparation}

Certain amounts of PVDF/diluent were weighted into a test tube, which was purged with argon and sealed to prevent oxidation during melt blending. The weight fraction of PVDF was fixed at $30 \mathrm{wt} \%$. The sealed test tube was heated in an oven at $200{ }^{\circ} \mathrm{C}$ for $48 \mathrm{~h}$ to yield a homogeneous solution. The tube was scrapped, and the homogeneous solution was quenched into liquid nitrogen to obtain a PVDF/diluent sample for differential scanning calorimetry (DSC) measurement.

\subsection{Cloud Point and DSC Determination}

The cloud points of the PVDF/diluent system were determined using a method reported before [8]. Non-isothermal crystallization behavior was studied using a DSC (Q100, TA, New Castle, DE, USA). All DSC measurements were performed under the nitrogen atmosphere, and sample weights varied 
from 5 to $9 \mathrm{mg}$. The sample was first heated to $200^{\circ} \mathrm{C}$ and maintained there for $10 \mathrm{~min}$ to erase thermal history, and then cooled to $40^{\circ} \mathrm{C}$ at a rate of $2,5,10$ and $20^{\circ} \mathrm{C} / \mathrm{min}$. The exothermic curves of heat flow with temperature decreasing at various rates were recorded and investigated. The crystallization half-time $\left(t_{1 / 2}\right)$, which is defined as the half-time of crystallization, was used as a characteristic parameter of the crystallization process.

The melting process of PVDF from the PVDF/diluent sample cooled at the different rates mentioned above was detected by maintaining at $40{ }^{\circ} \mathrm{C}$ for $2 \mathrm{~min}$, followed by heating to $200{ }^{\circ} \mathrm{C}$ at a rate of $10{ }^{\circ} \mathrm{C} / \mathrm{min}$. The absolute crystallinity of $\operatorname{PVDF}\left(\chi_{\mathrm{c}}\right)$ is as recorded below [20]:

$$
\mathrm{X}_{c}=\frac{\Delta H_{f} / \phi}{\Delta H_{f}^{*}} \times 100 \%
$$

where $\Delta H_{f}^{*}=104.5 \mathrm{~J} / g$ is the melting enthalpy for a $100 \%$ crystalline PVDF, $\Delta H_{f}$ is the melting enthalpy of the PVDF/diluent sample measured in DSC and $\omega$ is the PVDF weight fraction.

\subsection{Avrami Analysis Modified by Jeziorny}

The Avrami analysis modified by Jeziorny [21] is an extended expression to analyze the non-isothermal crystallization process. The Avrami equation was modified as follows:

$$
\log \{-\ln \{1-X(t)\}\}=\log Z_{t}+n \log t
$$

where $n$ is the Avrami exponent, $Z_{t}$ is the Avrami rate constant involving nucleation and growth parameters and $X(t)$ is the relative degree of crystallinity at the time $t$, which was obtained from the area of the DSC exothermic peak at time $t$ divided by the total area under the exothermic peak, as shown in Equation (3):

$$
X(\mathrm{t})=\int_{t_{0}}^{t}(d H / d t) d t / \int_{t_{0}}^{t_{\infty}}(d H / d t) d t
$$

where $t_{o}$ and $t_{\infty}$ represent the onset and end of crystallization temperatures respectively, and $d H / d t$ is the heat flow rate.

\subsection{Mo's Approach Analysis}

By combining the Ozawa analysis [22] and modified Avrami analysis, Mo [23] obtained another kinetic equation for non-isothermal crystallization behavior to relate the crystallinity with the cooling rate, $\phi$, and the crystallization time, $t$. The relationship between $\phi$ and $t$ was defined for a given degree of crystallinity as follows.

$$
\log \phi=\log F(t)-b \log t
$$

where the parameter $F(t)$ refers to the necessary value of the cooling rate to reach a defined crystallinity within unit crystallization time, and $b$ is the ratio between Avrami and Ozawa exponents. From Equation (4), it is followed that, at a given crystallinity, the plot of $\log \phi$ versus $\log t$ should be a straight line with an intercept of $\log F(t)$ and a slope of $-b$.

\subsection{Membrane Preparation and Sem Observation}

The PVDF/dialkyl phthalate sample obtained in the manner mentioned above was re-heated to $200{ }^{\circ} \mathrm{C}$ for $5 \mathrm{~min}$, and then quenched into ice-water to induce phase separation and polymer solidification. The diluent that remained in the membrane precursor was extracted by ethanol, and the PVDF membrane was obtained after the volatilization of ethanol. 
The resulting PVDF membrane was fractured in liquid nitrogen and coated with platinum. A scanning electron microscope (SEM, JSM7401, JEOL Ltd., Akishima, Japan) with the accelerating voltage set to $1.0 \mathrm{kV}$ was used to examine the cross-section of membranes.

\section{Results and Discussion}

\subsection{Non-Isothermal Crystallization Behavior}

No cloud points were found and only the crystallization (solid-liquid phase separation) occurred in these three PVDF/dialkyl phthalate systems because dialkyl phthalates had good compatibility with PVDF. Figure 1 shows the exothermic curves for PVDF/dialkyl phthalate blends at different cooling rates. Table 1 summarizes how the crystallization temperature and the value of enthalpy of crystallization for PVDF/dialkyl phthalate blends depended upon the alkyl chain-length of dialkyl phthalate. The melting data are listed in Table 2, which were obtained from the melting thermograms shown in Figure 2. It clearly shows that an increase of the alkyl chain-length of dialkyl phthalate accelerated the crystallization of PVDF progressively. The onset crystallization temperature, $t_{c}{ }^{0}$, peak crystallization temperature, $t_{c}{ }^{p}$, and final crystallization temperature, $T_{c}{ }^{f}$, all increased with the increase of the alkyl chain-length of dialkyl phthalate. The crystallization behavior of the PVDF/dialkyl phthalate blend was analyzed in terms of the compatibility between PVDF and dialkyl phthalate. The degree of compatibility could be estimated from the different interaction parameter, $\chi_{12}$, between polymer and diluent using the following expression [24]:

$$
\chi_{12}=\frac{V_{m}}{R T}\left[\left(\delta_{d 1}-\delta_{d 2}\right)^{2}+0.25\left(\delta_{p 1}-\delta_{p 2}\right)^{2}+0.25\left(\delta_{h 1}-\delta_{h 2}\right)^{2}\right]
$$

where $R$ is the ideal gas constant $(8.314 \mathrm{~J} / \mathrm{mol} / \mathrm{K}), T$ is the environment temperature $(298 \mathrm{~K})$, and $\delta_{d}$, $\delta_{p}$ and $\delta_{h}$ are the Hansen's parameters for dispersion, polar and hydrogen bonding interactions, respectively [25]. $V_{m}$ is the molar volume of the diluent. In general, the larger the interaction parameter, $\chi_{12}$, value, the weaker the compatibility between the polymer and diluents.

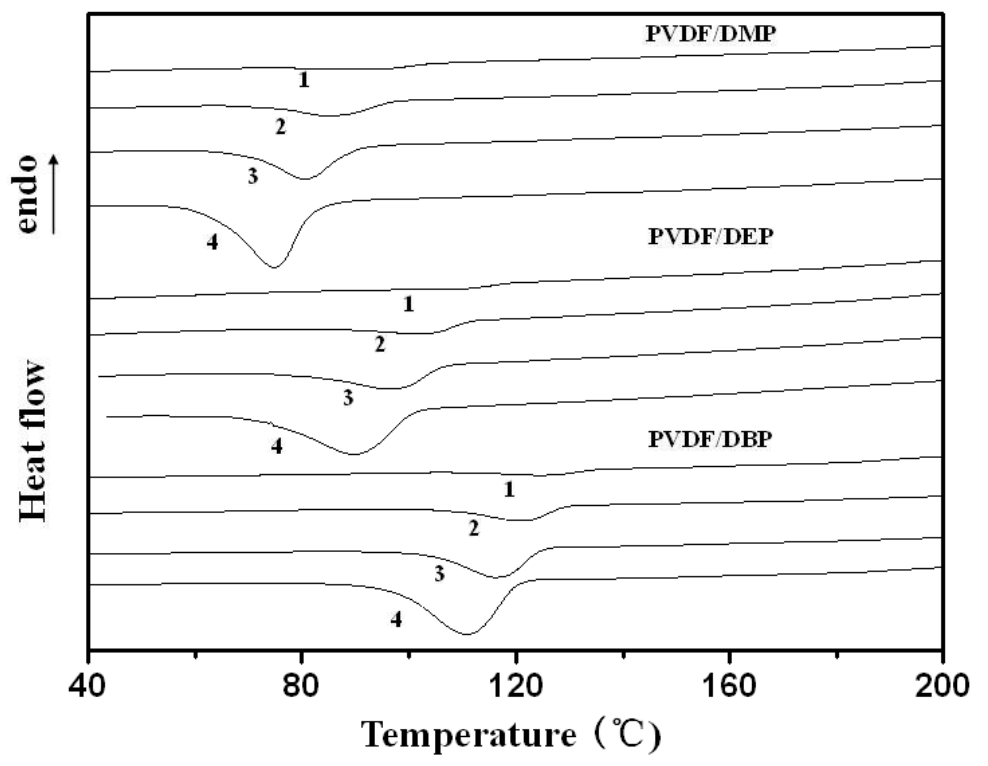

Figure 1. Differential scanning calorimetry (DSC) curves of the non-isothermal crystallization of Poly(vinylidene fluoride) (PVDF)/dialkyl phthalate blends at different cooling rates: (1) 2, (2) 5, (3) 10 and (4) $20^{\circ} \mathrm{C} / \mathrm{min}$. 


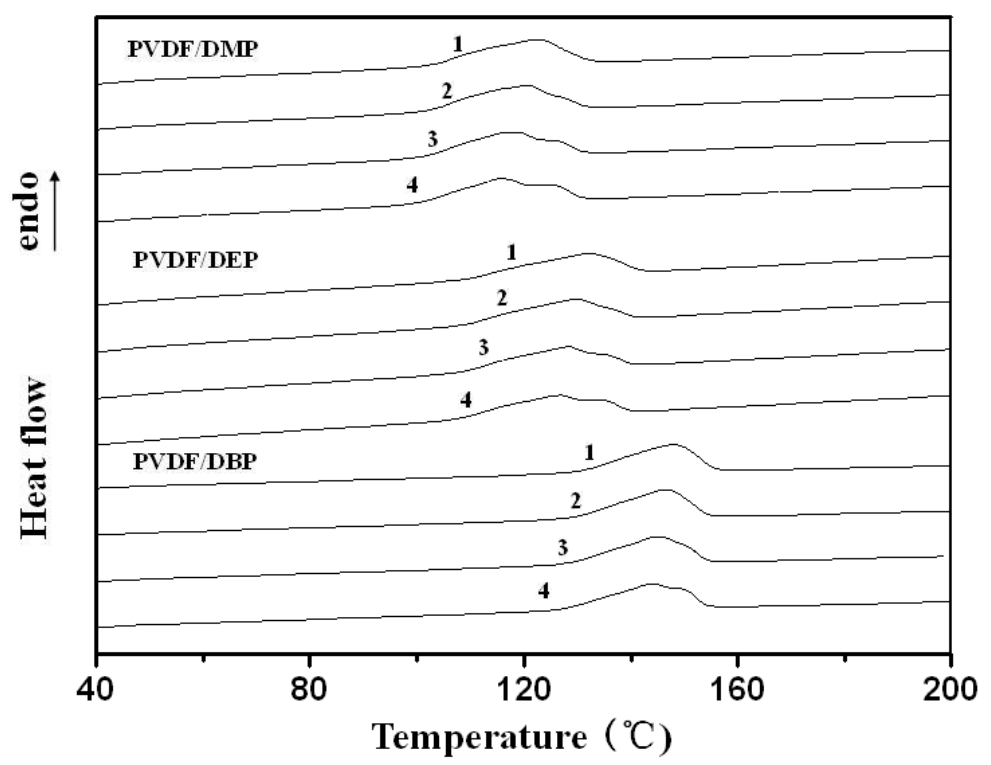

Figure 2. DSC scans showing the melting traces of PVDF/dialkyl phthalate blends at the rate of $10^{\circ} \mathrm{C} / \mathrm{min}$.

Table 2 shows the interaction parameter, $\chi_{12}$, value between PVDF and dialkyl phthalate. As a result, with the increase of the alkyl chain-length of dialkyl phthalate, the interaction parameter, $\chi_{12}$, value increased, which indicated the decrease of the compatibility between PVDF and the diluent. Favorable compatibility induced full extension of PVDF segments, which led to the required higher supercooling degree for PVDF segments to fold when cooling at the same rate. Namely, the crystallization temperature of PVDF decreased with the decrease of the alkyl chain-length of dialkyl phthalate.

Table 1. DSC crystallization and melting results of PVDF/dialkyl phthalate blends.

\begin{tabular}{|c|c|c|c|c|c|c|c|c|c|c|}
\hline Sample & $\begin{array}{c}\phi \\
(\% / \min )\end{array}$ & $\begin{array}{l}T_{c}{ }^{o n} \\
\left({ }^{\circ} \mathrm{C}\right)\end{array}$ & $\begin{array}{l}T_{c}{ }^{p} \\
\left({ }^{\circ} \mathrm{C}\right)\end{array}$ & $\begin{array}{l}T_{c}^{f} \\
\left({ }^{\circ} \mathrm{C}\right)\end{array}$ & $\begin{array}{l}T_{m}{ }^{o n} \\
\left({ }^{\circ} \mathrm{C}\right)\end{array}$ & $\begin{array}{l}T_{m}{ }^{p} \\
\left({ }^{\circ} \mathrm{C}\right)\end{array}$ & $\begin{array}{l}T_{m}^{f} \\
\left({ }^{\circ} \mathrm{C}\right)\end{array}$ & $\begin{array}{l}\Delta H_{m} \\
(\mathrm{~J} / \mathrm{g})\end{array}$ & $\begin{array}{c}X_{c} \\
(\%)\end{array}$ & $\begin{array}{c}t_{1 / 2} \\
(\mathrm{~min})\end{array}$ \\
\hline PVDF/DMP & 2 & 108.5 & 94.7 & 75.4 & 100.2 & 122.5 & 135.2 & 62.7 & 60.0 & 8.0 \\
\hline PVDF/DEP & 2 & 121.7 & 109.5 & 88.4 & 109.6 & 131.4 & 144.1 & 59.8 & 57.2 & 7.2 \\
\hline PVDF/DBP & 2 & 138.8 & 125.4 & 106.8 & 125.3 & 148.0 & 159.0 & 58.4 & 55.9 & 7.1 \\
\hline PVDF/DMP & 5 & 100.4 & 85.3 & 63.5 & 100.4 & 120.6 & 133.7 & 61.3 & 58.6 & 3.2 \\
\hline PVDF/DEP & 5 & 114.3 & 102.8 & 76.1 & 107.6 & 129.5 & 141.6 & 60.4 & 57.8 & 3.0 \\
\hline PVDF/DBP & 5 & 133.9 & 120.6 & 98.7 & 123.6 & 146.4 & 157.5 & 58.2 & 55.7 & 2.5 \\
\hline PVDF/DMP & 10 & 98.5 & 80.7 & 57.9 & 95.3 & 116.7 & 133.2 & 65.6 & 62.7 & 1.9 \\
\hline PVDF/DEP & 10 & 111.1 & 97.0 & 68.7 & 105.5 & 127.9 & 140.9 & 61.7 & 59.0 & 1.7 \\
\hline PVDF/DBP & 10 & 129.0 & 116.6 & 91.6 & 123.0 & 145.2 & 155.6 & 57.0 & 54.5 & 1.4 \\
\hline PVDF/DMP & 20 & 91.2 & 75.0 & 52.6 & 97.4 & 115.5 & 133.0 & 62.7 & 60.0 & 1.0 \\
\hline PVDF/DEP & 20 & 107.9 & 90.0 & 62.89 & 105.7 & 126.4 & 140.9 & 60.7 & 58.1 & 0.9 \\
\hline PVDF/DBP & 20 & 126.0 & 110.8 & 84.6 & 123.4 & 144.0 & 155.8 & 57.2 & 54.8 & 0.8 \\
\hline
\end{tabular}

DMP: dimethyl phthalate; DEP: diethyl phthalate; DBP: dibutyl phthalate; $\phi$ : Heating/cooling rate; $T_{c}{ }^{\text {on }}$ : onset crystallization temperature; $T_{c}{ }^{p}$ : peak crystallization temperature; $T_{c}{ }^{f}$ : final crystallization temperature; $T_{m}{ }^{\text {on }}$ : onset melting temperature; $T_{m}{ }^{p}$ : peak melting temperature; $T_{m}{ }^{f}$ : final melting temperature; $\Delta H_{m}$ measured melting enthalpy from DSC; $X_{c}$ : crystallinity; $t_{1 / 2}$ : half-time.

Table 2. Hansen solubility parameters of PVDF and dialkyl phthalate and their interaction parameters.

\begin{tabular}{cccccc}
\hline Substance & $\boldsymbol{\delta}_{\mathbf{d}}\left(\mathbf{M P a}^{\mathbf{1} / \mathbf{2}}\right)$ & $\boldsymbol{\delta}_{\mathbf{p}}\left(\mathbf{M P a}^{\mathbf{1} / \mathbf{2}}\right)$ & $\boldsymbol{\delta}_{\mathbf{h}}\left(\mathbf{M P a}^{\mathbf{1} / \mathbf{2}}\right)$ & $V_{\boldsymbol{m}}\left(\mathbf{c m}^{\mathbf{3}} / \mathbf{m o l}\right)$ & $\chi_{12}$ \\
\hline PVDF & 17.0 & 12.1 & 10.2 & - & - \\
DMP & 18.6 & 10.8 & 4.9 & 163.0 & 0.66 \\
DEP & 17.6 & 9.6 & 4.5 & 180.4 & 0.73 \\
DBP & 17.8 & 8.6 & 4.1 & 266.4 & 1.40 \\
\hline
\end{tabular}


Relative crystallinity, $X(t)$, as a function of the crystallization time, $t$, for PVDF/dialkyl phthalate blends is plotted in Figure 3. As would be expected, PVDF at higher cooling rates required a shorter time to complete crystallization. From these curves, it was easy to find that PVDF/dialkyl phthalate blends showed similar development of the crystallization process, and a series of S-shaped curves were obtained due to the spherulitic impingement in the later crystallization stage. The crystallization half-time, $t_{1 / 2}$, which represents the overall crystallization rate, is defined as the time at which the relative crystallization degree is $50 \%$ completed. The shorter the half-time, $t_{1 / 2}$, the faster the overall crystallization rate. As listed in Table 1 , it could be seen that, as expected, $t_{1 / 2}$ decreased with the increase of the cooling rate for all the cases. Moreover, $t_{1 / 2}$ decreased with the increase of the alkyl chain-length of dialkyl phthalate. As stated above, with the increase of the alkyl chain-length of dialkyl phthalate, the compatibility between PVDF and dialkyl phthalate became weaker, which led to a higher growth rate of PVDF crystallization.

(a)

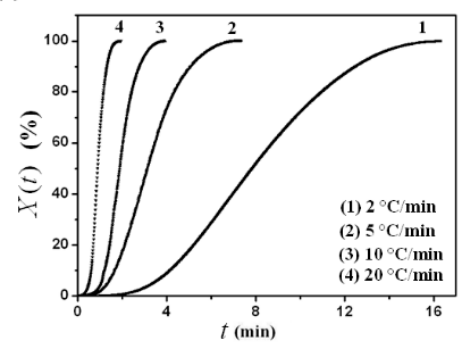

(b)

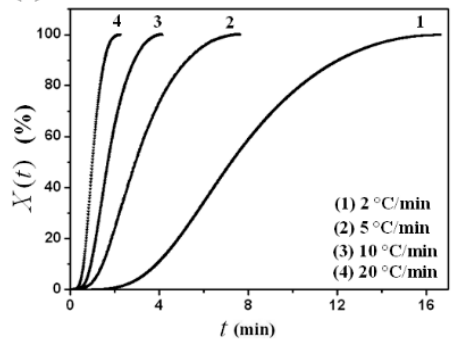

(c)

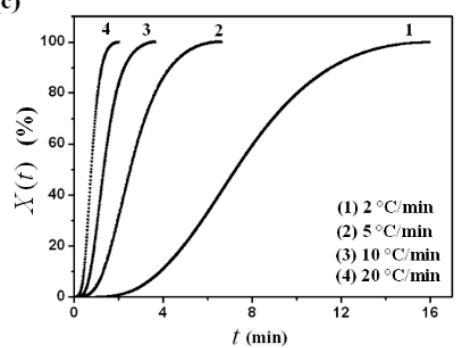

Figure 3. Relative crystallinity, $X(t)$, versus crystallization time, $t$, for (a) PVDF/DMP, (b) PVDF/DEP and (c) PVDF/DBP.

As listed in Table 1, the melting temperature was decreased with the decrease of the alkyl chain-length of dialkyl phthalate. As reported, depression of melting temperature, due to a decrease in the chemical potential of the crystalline polymer, could provide the information on compatibility between the polymer and diluent. The higher the depth of melting temperature depression that occurred, the better compatibility between the polymer and diluent $[26,27]$. So, it was also suggested that the compatibility between PVDF and dialkyl phthalate increased with the decrease of the alkyl chain-length of dialkyl phthalate.

\subsection{Avrami Analysis Modified by Jeziorny}

The Avrami plot of $\log \{-\ln \{1-X(t)\}\}$ versus $\log t$ for PVDF/dialkyl phthalate is shown in Figure 4. Each curve had a linear portion, most of which was followed by a gentle deviation at longer times. Usually, this deviation is considered to be due to the secondary crystallization, which is caused by the spherulite impingement in the later stage [28]. The calculated values of $n, Z_{t}$ and $Z_{c}$ for the linear portion are listed in Table 3. The Avrami exponent lies between 2.9 and 3.7. The values of crystallization rate parameter, $Z_{c}$, were comparable for every sample. At a specific cooling rate, the values of $Z_{c}$ for PVDF decreased with the decreasing alkyl chain-length of dialkyl phthalate. In the case of dialkyl phthalate having a shorter alkyl chain-length, favorable compatibility between PVDF and dialkyl phthalate induced full extension of PVDF segments, which brought resistance for the transport of the 
PVDF segment to the growing crystal surface and reduced the rate of crystallization growth. At the same time, the values of $Z_{c}$ increased with the increase of the cooling rate. Increasing the cooling rate could provide the system with more energy to improve the activity of the chain segment, thus resulting in the increase of crystallization rate parameter, $Z_{c}$.
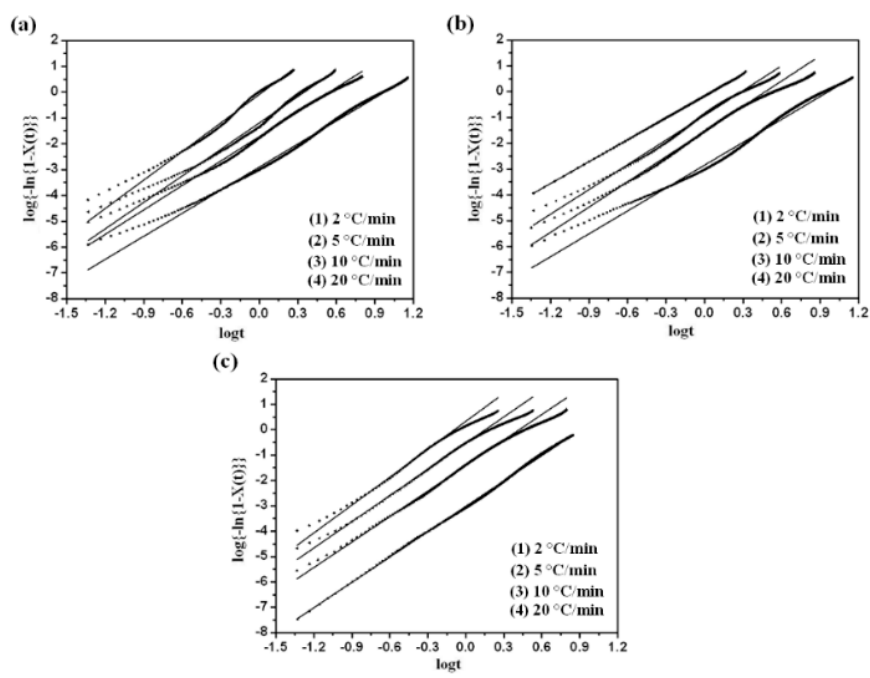

Figure 4. Modified Avrami plots of $\log \{-\ln \{1-X(t)\}\}$ versus $\log t$ for (a) PVDF/DMP, (b) PVDF/DEP and (c) PVDF/DBP.

Table 3. Kinetic parameters of PVDF/dialkyl phthalate blends from the modified Avrami analysis.

\begin{tabular}{crcc}
\hline Sample $\phi\left({ }^{\circ} \mathrm{C} /\right.$ min $)$ & $n$ & $Z_{t}$ & $Z_{\boldsymbol{c}}$ \\
\hline \multicolumn{5}{c}{ PVDF/DMP } & & \\
5 & 2.98 & 0.001 & 0.031 \\
10 & 3.16 & 0.019 & 0.453 \\
20 & 3.42 & 0.064 & 0.760 \\
& 3.69 & 0.820 & 0.990 \\
2 & PVDF/DEP & & \\
5 & 2.96 & 0.001 & 0.035 \\
10 & 3.26 & 0.029 & 0.492 \\
20 & 3.20 & 0.122 & 0.810 \\
& 2.83 & 0.989 & 0.999 \\
2 & PVDF/DBP & & \\
5 & 3.33 & 0.001 & 0.038 \\
10 & 3.35 & 0.039 & 0.522 \\
20 & 3.44 & 0.296 & 0.885 \\
& 3.67 & 2.149 & 1.039 \\
\hline
\end{tabular}

\subsection{Mo's Approach}

At a given degree of crystallinity, plotting $\log \phi$ versus $\log t$ (Figure 5) yielded a linear relationship between $\log \phi$ and $\log t$. The data of the kinetic parameter $F(t)$ and $b$ estimated from the intercept and slope for PVDF/dialkyl phthalate are listed in Table 4. For each sample, with the increase of relative crystallinity, $X(t)$, the values of $b$ changed slightly, while the values of $F(t)$ increased, indicating that at a given crystallization time, a higher cooling rate should be used to obtain a higher degree of crystallinity. However, at the same $X(t)$, the values of $F(t)$ decreased with the increase of the alkyl chain-length of dialkyl phthalate. Namely, the increase of compatibility between PVDF and dialkyl phthalate could reduce the crystallization rate, and this was consistent with the analysis of crystallization half-time and the Avrami analysis modified by Jeziorny. 
(a)

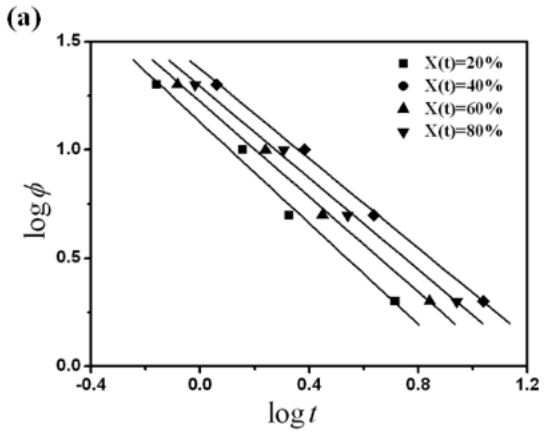

(b)

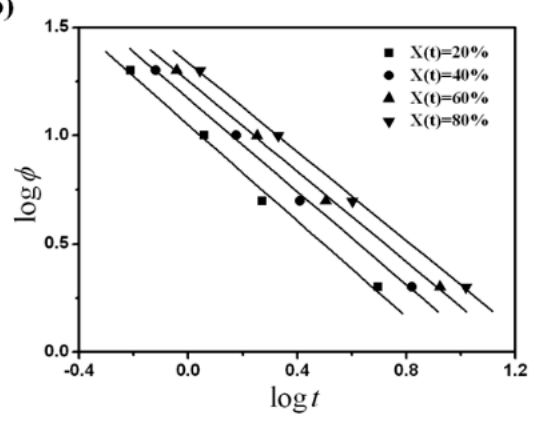

(c)

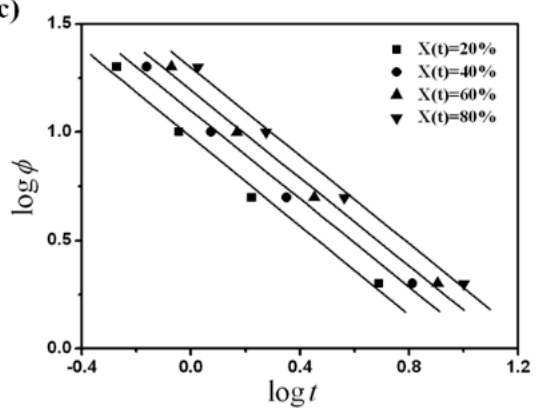

Figure 5. Plots of $\log \phi$ versus $\log t$ from Mo's analysis for (a) PVDF/DMP, (b) PVDF/DEP and (c) PVDF/DBP.

Table 4. Values of $b$ and $F(t)$ at various values of $X(t)$ for PVDF/dialkyl phthalate blends.

\begin{tabular}{ccccc}
\hline $\boldsymbol{X}(\boldsymbol{t})$ & $\mathbf{2 0} \%$ & $\mathbf{4 0} \%$ & $\mathbf{6 0} \%$ & $\mathbf{8 0} \%$ \\
\hline \multicolumn{5}{c}{ PVDF/DMP } \\
$b$ & 1.17 & 1.10 & 1.06 & 1.03 \\
$F(t)$ & 13.42 & 16.69 & 19.63 & 23.60 \\
\multicolumn{5}{c}{ PVDF/DEP } \\
$b$ & 1.11 & 1.07 & 1.04 & 1.03 \\
$F(t)$ & 11.24 & 14.83 & 17.89 & 21.75 \\
5 & PVDF/DBP \\
$b$ & 1.03 & 1.02 & 1.01 & 1.02 \\
$F(t)$ & 9.52 & 12.55 & 15.62 & 19.89 \\
$X(t)$ & $20 \%$ & $40 \%$ & $60 \%$ & $80 \%$ \\
$b$ & 1.17 & PVDF/DMP & \\
$b$ & 1.10 & 1.06 & 1.03
\end{tabular}

$F(t)$ : the necessary value of the cooling rate to reach a defined crystallinity within unit crystallization time; $b$ : the ratio between Avrami and Ozawa exponents.

\subsection{Membrane Structure}

Figure 6 shows the cross-section structure of the membranes prepared from PVDF/dialkyl phthalate systems via the TIPS method. Each sample presented spherulitic structure due to only solid-liquid phase separation occurring. With the decrease of the alkyl chain-length of dialkyl phthalate, the number of spherulites increased and the size of spherulites became smaller. As mentioned above, while the alkyl chain-length of dialkyl phthalate decreased, the onset crystallization temperature, $t_{c}{ }^{\circ}$, decreased, which resulted in more nuclei formation at the beginning of crystallization. Therefore, these nuclei grew up into smaller spherulites with the same polymer concentration. 

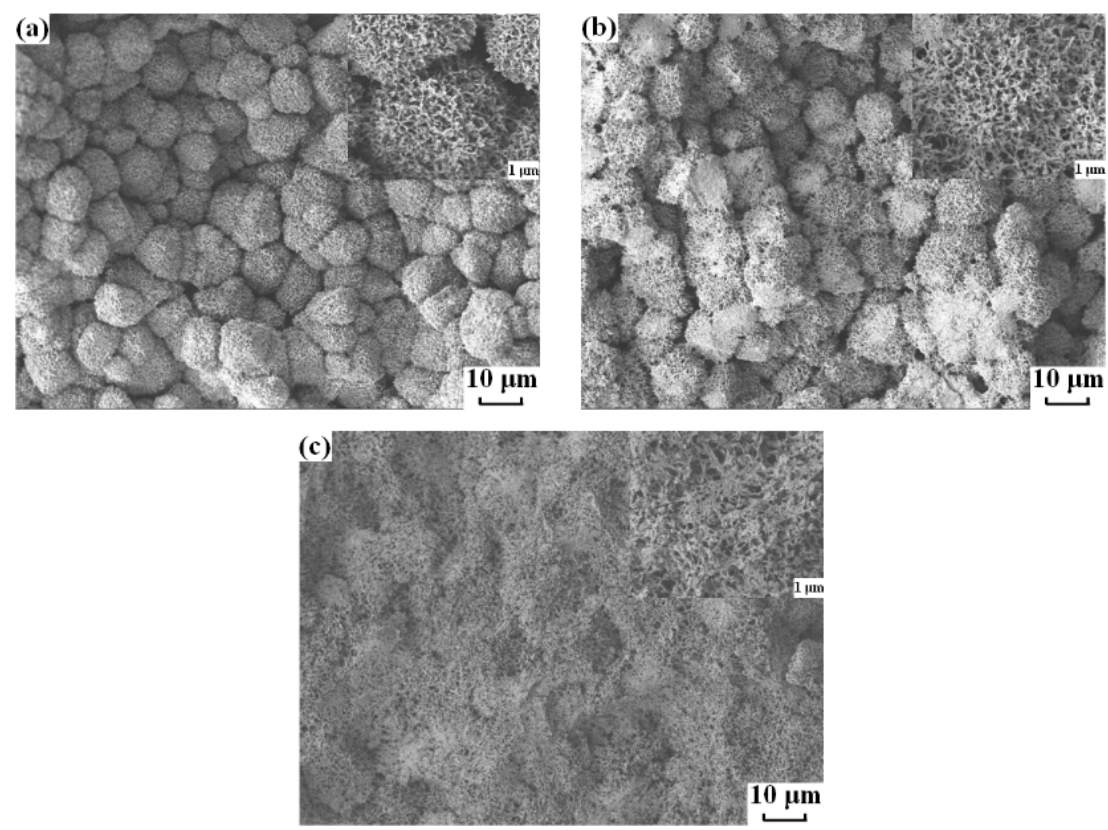

Figure 6. Scanning electron microscopy (SEM) photographs of cross-sections of PVDF membranes prepared by quenching PVDF/dialkyl phthalate solutions into ice-water: (a) PVDF/DMP, (b) PVDF/DEP and (c) PVDF/DBP.

\section{Conclusions}

With the DSC data obtained at various cooling rates, the effect of the alkyl chain-length of dialkyl phthalate on the non-isothermal crystallization behavior of PVDF/dialkyl phthalate blends during the TIPS process was investigated through the Avrami analysis modified by Jeziorny and Mo's analysis. DSC exotherms of non-isothermal crystallization showed that all the crystallization temperatures $\left(t_{c}{ }^{0}, t_{c}{ }^{p}\right.$ and $\left.t_{c}{ }^{f}\right)$ increased with the increasing alkyl chain-length of dialkyl phthalate. On the other hand, $t_{1 / 2}$ increased as the alkyl chain-length of dialkyl phthalate and the cooling rate decreased. With the increase of the alkyl chain-length of dialkyl phthalate, the parameter $Z_{c}$ increased and $F(t)$ decreased, which revealed that the crystallization rate increased. SEM results showed that the cross-section of the PVDF membrane prepared from the PVDF/dialkyl phthalate system presented spherulitic structure due to the solid-liquid phase separation occurring. Moreover, the number of spherulites increased and the size of spherulites became smaller with the decrease of the alkyl chain-length of dialkyl phthalate.

Author Contributions: Conceptualization, Y.L.; X.W.; methodology, Y.L.; investigation, Y.L.; data curation, Y.L.; writing — original draft preparation, Y.L. and L.W.; writing-review and editing, Y.T.; supervision, X.W.; project administration, Y.T.; funding acquisition, Y.T. and X.W. All authors have read and agreed to the published version of the manuscript.

Funding: This work was financially supported by Key Projects of the National Science and Technology Pillar Program of China (2015BAE06B00) and Open Project of State Key Laboratory of Chemical Engineering of China (SKL-CHE-19A02).

Conflicts of Interest: The authors declare no conflict of interset.

\section{References}

1. Castro, J. Method for Making Microporous Products. U.S. Patent 4,247,498, 27 January 1981.

2. Kim, S.S.; Lloyd, D.R. Thermodynamics of Polymer/Diluent Systems for Thermally Induced Phase Separation: 2.Solid-Liquid Phase Separation Systems. Polymer 1992, 33, 1036-1046. [CrossRef]

3. Dohany, J.E. Fluorine-Containing Polymers, Poly(Vinylidene Fluoride). Kirk Othmer Encycl. Chem. Technol. 2000, S118-S119. [CrossRef] 
4. Kang, G.; Cao, Y.M. Application and modification of poly(vinylidene fluoride) (PVDF) membranes-A review. J. Membr. Sci. 2014, 463, 145-165. [CrossRef]

5. Rajabzadeh, S.; Maruyama, T.; Sotani, T.; Matsuyama, H. Preparation of PVDF hollow fiber membrane from a ternary polymer/solvent/nonsolvent system via thermally induced phase separation (TIPS) method. Sep. Purif. Technol. 2008, 63, 415-423. [CrossRef]

6. Yang, J.; Zhao, W.M.; Wang, X.L. Diluent selection of PVDF membrane prepared via thermally induced phase separation. Chem. J. Chin. Univ. Chin. 2008, 29, 1895-1900.

7. Yang, J.; Li, D.W.; Lin, Y.K.; Wang, X.L.; Tian, F.; Wang, Z. Formation of a bicontinuous structure membrane of polyvinylidene fluoride in diphenyl ketone diluent via thermally induced phase separation. J. Appl. Polym. Sci. 2008, 110, 341-347. [CrossRef]

8. Lin, Y.; Tang, Y.; Ma, H.; Yang, J.; Tian, Y.; Ma, W.; Wang, X. Formation of a bicontinuous structure membrane of polyvinylidene fluoride in diphenyl carbonate diluent via thermally induced phase separation. J. Appl. Polym. Sci. 2009, 114, 1523-1528. [CrossRef]

9. Tang, Y.; Lin, Y.; Ma, W.; Tian, Y.; Yang, J.; Wang, X. Preparation of microporous PVDF membrane via tips method using binary diluent of DPK and PG. J. Appl. Polym. Sci. 2010, 118, 3518-3523. [CrossRef]

10. Cui, Z.Y.; Du, C.H.; Xu, Y.Y.; Ji, G.L.; Zhu, B.K. Preparation of porous PVdF membrane via thermally induced phase separation using sulfolane. J. Appl. Polym. Sci. 2008, 108, 272-280. [CrossRef]

11. Ishigami, T.; Nii, Y.; Ohmukai, Y.; Rajabzadeh, S.; Matsuyama, H. Solidification Behavior of Polymer Solution during Membrane Preparation by Thermally Induced Phase Separation. Membranes 2014, 4, 113-122. [CrossRef]

12. Song, Z.; Yang, W.; Zhang, J.; Li, Y.; Yuan, S. Fabrication of hollow fiber microfiltration membrane from PVDF/DBP/DBS system via thermally induced phase separation process. J. Polym. Eng. 2015, 35, $709-717$. [CrossRef]

13. Wu, L.; Sun, J. An improved process for polyvinylidene fluoride membrane preparation by using a water soluble diluent via thermally induced phase separation technique. Mater. Des. 2015, 86, 204-214. [CrossRef]

14. Wang, L.; Huang, D.; Wang, X.; Meng, X.; Lv, Y.; Wang, X.; Miao, R. Preparation of PVDF membranes via the low-temperature TIPS method with diluent mixtures: The role of coagulation conditions and cooling rate. Desalination 2015, 361, 25-37. [CrossRef]

15. Zhou, Q.; Wang, Z.; Shen, H.; Zhu, Z.; Liu, L.; Yang, L.; Cheng, L. Morphology and performance of PVDF TIPS microfiltration hollow fiber membranes prepared from PVDF/DBP/DOP systems for industrial application. J. Chem. Technol. Biotechnol. 2016, 91, 1697-1708. [CrossRef]

16. Zhou, Q.H.; Shen, H.H. Effect of Diluent Mixing Ratio on PVDF Hollow Fiber Membrane Fabricated by Thermally Induced Phase Separation. China Plast. 2017, 31, 87-94.

17. Cui, Z.; Xu, S.; Ding, J.; Zhang, J.; He, B.; Wang, H.; Li, J. The Effect of Diluent Mixture with Upper Critical Solution Temperature on Membrane Formation Process, Microstructure, and Performance of PVDF Hollow Fiber Membrane by TIPS Process. Polymers 2018, 10, 719. [CrossRef]

18. Liu, Z.; Pan, Q.; Gao, J.; Xiao, C. Effect of Mixed Solvents on the Structure of Polyvinylidene Fluoride Flat Membrane in Thermally Induced Phase Separation Method. J. Nanosci. Nanotechnol. 2019, 19, 5994-5998. [CrossRef]

19. Ji, G.L.; Zhu, B.K.; Zhang, C.F.; Xu, Y.Y. Nonisothermal Crystallization Kinetics of Poly(vinylidene fluoride) in a Poly(vinylidene fluoride)/Dibutyl Phthalate/Di(2-ethylhexyl)phthalate System via Thermally Induced Phase Separation. J. Appl. Polym. Sci. 2008, 107, 2109-2117. [CrossRef]

20. Gu, M.; Zhang, J.; Wang, X.; Ma, W. Crystallization Behavior of PVDF-DMP System via Thermally Induced Phase Separation. J. Appl. Polym. Sci. 2006, 102, 3714-3719. [CrossRef]

21. Jeziorny, A. Parameters Characterizing the Kinetics of the Non-isothermal Crystallization of Poly(ethylene terephthalate) Determined by DSC. Polymer 1978, 19, 1142-1144. [CrossRef]

22. Ozawa, T. Kinetic of Non-isothermal crystallization. Polymer 1971, 12, 150-158. [CrossRef]

23. Qiu, Z.; Mo, Z.; Yu, Y.; Zhang, H.; Sheng, S.; Song, C. Nonisothermal melt and cold crystallization kinetics of poly(aryl ether ketone ether ketone ketone). J. Appl. Polym. Sci. 2000, 77, 2865-2871. [CrossRef]

24. Liu, B.; Du, Q.G.; Yang, Y.L. The phase diagrams of mixtures of EVAL and PEG in relation to membrane formation. J. Membr. Sci. 2000, 180, 81-92. [CrossRef]

25. Hansen, C.M. Hansen Solubility Parameters; CRC Press: Boca Raton, FL, USA, 2000; pp. 168-200. 
26. Nishi, T.; Wang, T. TMelting Point Depression and Kinetic Effects of Cooling on Crystallization in Poly(vinylidene fluoride)-Poly(methyl methacrylate) Mixtures. Macromolecules 1975, 8, 909-915. [CrossRef]

27. Wang, T.T.; Nishi, T. Spherulitic Crystallization in Compatible Blends of Poly(vinylidene fluoride) and Poly(methyl methacrylate). Macromolecules 1977, 10, 421-425. [CrossRef]

28. Zhang, H.F.; Zhang, Q.B.; Sun, C.Y. Nonisothermal crystallization kinetics of polypropylene/polyethersulfone blend. Polym. Bull. 2008, 60, 291-300. [CrossRef]

(C) 2020 by the authors. Licensee MDPI, Basel, Switzerland. This article is an open access article distributed under the terms and conditions of the Creative Commons Attribution (CC BY) license (http://creativecommons.org/licenses/by/4.0/). 